\title{
KESENIAN DONGKREK \\ (STUDI NILAI BUDAYA DAN POTENSINYA SEBAGAI SUMBER PENDIDIKAN KARAKTER)
}

\author{
Muhammad Hanif \\ Program Magister PIPS IKIP PGRI MADIUN \\ Email: muhhanieff@yahoo.com
}

\begin{abstract}
Abstrak
Penelitian ini bertujuan untuk menganalisis dan mendeskripsikan nilai budaya kesenian Dongkrek Madiun dan potensinya yang dapat dijadikan sumber pendidikan karakter.Penelitian ini menggunakan pendekatan kualitatif etnografis dengan menggunakan sumber data primer dan skunder. Informan ditentukan dengan purposive sampling. Pengumpulan datanya menggunakan wawancara, observasi, pencatatan dokumentasi. Sedangkan analisis datanya dengan Teknik Coding Model Strauss dan Corbin. Hasil penelitian menggambarkan bahwa kesenian dongkrek memiliki nilai-nilai; kerohanian, spiritual, moral, kepahlawanan, kepemimpinan, keadilan, kesejahteraan, dan estetika. Nilainilai secara fungsional dan eksperimental berpotensi untuk dijadikan sebagai sumber pendidikan karakter terutama dalam penegakan nilai-nilai kemasyarakatan dan menumbuhkembangkan kepemimpinan, kepahlawanan, keikhlasan, dan kesetiaan.
\end{abstract}

Kata kunci: Dongkrek, Nilai Budaya, Pendidikan Karakter

A PERFORMANCE ART 'DONGKREK'

\section{(A Study of Cultural Values and Their Potential as Sources of Character Education)}

\begin{abstract}
The research aims to analyze and describe cultural values of a performance art 'DONGKREK' originally from Madiun and their potential that can be used as sources of character education. The research uses qualitative of ethnography based on primary and secondary data sources. Informants are determined through purposive sampling. Data collection are done through interview, observation, and documentation. Further, the data are analyzed through Strauss and Corbin's Coding technique. The results describe that a performing art 'DONGKREK' has some values namely leadership, fairness, prosperity, and aesthetics. In the functional and experimental point of view, the values have potential for becoming sources of character education especially in terms of establishing society values and developing leadership, heroism, whole-heartedness, and loyalty.
\end{abstract}

Keywords: A performing art 'DONGKREK', cultural values, potential, character education

\section{Pendahuluan}

Kehidupan masyarakat Indonesia di era globalisasi dan Masyarakat Ekonomi Asia (MEA) dewasa ini mengalami perubahan menuju masyarakat baru yang beranjak ke arah reunifikasi dan unsur- unsur budaya asing masuk dan bersanding dengan kebudayaan lokal semakin tidak terhindarkan. Jika masyarakat tidak selektif dalam interaksi dengan budaya luar dan kurangnya kesadaran terhadap kebudayaan yang telah dimilikinya, maka kebudayaan lokal atau nasional yang 


\section{gulawentah: Jurnal Studi Sosial}

Volume 1 Nomor 2 Desember 2016, hal. 132-141

Avaliable online at http://e-journal.ikippgrimadiun.ac.id/index.php/gulawentah

merupakan identitas dan jati diri lambat laun akan pudar. Sebaliknya, jika masyarakat memiliki kemampuan melestarikan dan menjaga kebudayaan lokal atau nasional, maka budaya luar menjadikan unsur-unsur mendorong kebudayaan ke arah yang lebih maju dan modern.

Salah satu unsur kebudayaan yang banyak menarik perhatian masyarakat dewasa ini yaitu kesenian dengan segala manivestasinya.Kesenian merupakan bagian dari kebudayaan namun acapkali kesenian menjadi tema kajian budaya. Hal ini tersebut dikarekan kesenian memiliki bobot besar dalam kebudayaan, kesenian sarat dengan kandungan nilai-nilai budaya, bahkan menjadi wujud dan ekspresi yang menonjol dari nilai-nilai budaya. Hatta (2010) menyampaikan bahwakesenian diartikulasikan sesuai dengan tuntutan perkembangan sosial, sehingga mudah beradaptasi dan mendorong kepekaan umum terhadap nilai-nilai keanggungan seni.

Membicara tentang kesenian di Indonesia memerlukan pembatasan tersendiri karena tidak hanya jumlahnya yang banyak tetapi juga bentuk dan karakteristiknya yang berbeda-beda. Salah satu kesenian tersebut yaitu kesenian Dongkrek. Kesenian Dongkrek ini merupakan kesenian tradisional khas Madiun dan menjadi kebanggaan masyarakat. Namun dalam perkembangannya di era dewasa ini kurang menggembirakan. Kesenian Dongkrek kurang diminati dan jarang dipertunjukkan. Padahal kesenian Dongkrek sudah hidup di tengah-tengah masyarakat dalam kurun waktu yang relatif lama. Hal ini tersebut tentunya sangat berkaitan dengan nilainilai yang dimilikinya sehingga masyarakat melestarikan dan mendukungnya sebab kelangsungan suatu kebudayaan akan sangat tergantung pada masyarakat pendukungnya.

Kesenian Dongkrek sebagai kesenian tradisional pada umumnya dalam proses penciptaannya ada nilai yang diusung dan disampaikan kepada masyarakat untuk dijadikan referensi menyikapi masalah. Nilai-nilai inilah yang belum banyak diketahui dan dipahami oleh masyarakat terutama generasi muda sehingga perlu diungkapkan melalui penelitian.Masalah ini penting dilakukan karena tidak sedikit masyarakat yang menontoh pertunjukkan kesenian Dongkrek hanya sebatas menikmati tariannya, bahkan menonton yang nonton dan belum memahami nilainilainya. Hal tersebut akan berakibat pada kehilangan makna dan ujung-ujungnya menjadi tidak lestari serta timbulnya masalah-masalah sosial yang dilatarbelakangi oleh degradasi nilai dan moral. Padahal kesenian tradisional di Indonesia pada umumnya mengandung nilai-nilai adiluhung dan berpotensi sebagai sumber pendidikan karakter. Oleh karena itu penelitian ini menarik dan perlu dilaksanakan.

Berdasarkan uraian di atas maka penelitian ini difokuskan pada nilai-nilai apa saja yang dimiliki kesenian Dongkrek dan potensinya sebagai sumber membangun karakter generasi muda. Adapun tujuan penelitian ini adalah; (1) menemukenali nilai budaya kesenian Dongkrek, (2) menganalisis dan mendeskripsikan nilai-nilai kesenian Dongkrek yang berpotensi untuk dijadikan 


\section{gulawentah: Jurnal Studi Sosial}

Volume 1 Nomor 2 Desember 2016, hal. 132-141

Avaliable online at http://e-journal.ikippgrimadiun.ac.id/index.php/gulawentah

sumber pembangun dan pengarah bagi masyarakat terutama generasi muda agar dapat bersikap dan bertindak sesuai dengan kaidah-kaidah dan spirit nilai-nilai adiluhung.

Kesenian Dongkrek termasuk kesenian tradisional yaitu suatu hasil ekspresi hasrat manusia akan keindahan dengan latar belakang tradisi atau sistem budaya masyarakat pemilik kesenian tersebut. Koentjaraningrat (2009:166) menyampaikan bahwa kesenian adalah kompleksitas dari berbagai ide-ide, norma-norma, gagasan, nilai-nilai, serta peraturan dimana kompleks aktivitas dan tindakan tersebut berpola dari manusia itu sendiri dan pada umumnya berwujud berbagai benda-benda hasil ciptaan manusia. Sedangkan tradisional menurut Prestia dan Susetyo (2013) merupakan istilahturunan dari kata dasar tradisi yang memiliki arti adat kebiasaan turun-temurun yang masih dijalankan dalammasyarakat. Tradisional juga dimaknai sebagai sikap dan caraberpikir serta bertindak yang selalu berpegangteguh pada norma dan adat kebiasaan yang adasecara turuntemurun.Tradisi di dalamnya ada ciri kuat yaituselalu bertolak dari kedaan masa lalusebagai suatu situasi prosessosial yang unsur-unsurnya diwariskan. Hal ini sejalan dengan pendapat Sutiyono (2012:123) bahwa seni tradisi merupakan seni yang hidup sejak lama yang diwariskan secara turun temurun. Dengan demikian kesenian tradisional pada hakikatnya merupakansuatu hasil ekspresi hasrat manusia akan keindahan dengan latar belakang tradisi atau sistem budaya masyarakat pemilikkesenian tersebut.
Dalam karya seni tradisional tersirat pesan dari masyarakatnya berupa pengetahuan, gagasan, kepercayaan, nilai, norma sebagai nilai budaya. Nilai budaya menurut Uhi (2016:76-77) merupakan konsepsi umum yang terorganisir dan dapat mempengaruhi perilaku manusia dalam hubungannya dengan lingkungan alam dan sosial, serta dengan sang maha pencipta. Nilai budaya tersebut menurut Kluckhohn (dalam Koetjaraningrat, 2016: 156) dibangun ke dalam suatu sistem nilai budaya yang berupa pandangan hidup (word view) bagi manusia penganutnya dan berfungsi sebagai pedoman bagi sikap mental, cara berpikir, dan bertingkah laku.

Kesenian tradisional dengan kandungan nilai budaya sebagaimana disampaikan di atas berpotensi untuk dijadikan sumber pendidikan karakter.Pendidikan karakatermerupakan sistem yang menanamkan nilai-nilai karakter yang mengandung komponen pengetahuan, kesadaran individu, tekad, serta adanya kemauan dan tindakan untuk melaksanakan nilai-nilai, baik terhadap Tuhan Yang Maha Esa, diri sendiri, sesama manusia, lingkungan maupun bangsa, sehingga terwujud insan kamil (Aunillah, 2011:18-19). Hal serupa juga disampaikan Fakry Gafar (dalam Kesuma dkk, 2011:5) adalah sebuah proses transformasi nilai-nilai kehidupan untuk ditumbuhkembangkan dalam kepribadian sehingga menjadi satu dalam perilaku kehidupan agar senantiasa berpola pikir, berpola sikap dan berpola tindakan atau watak yang senantiasa positif.

Rujukan sebagai sumber yang harus dijadikan sebagai landasan dalam 


\section{gulawentah: Jurnal Studi Sosial}

Volume 1 Nomor 2 Desember 2016, hal. 132-141

Avaliable online at http://e-journal.ikippgrimadiun.ac.id/index.php/gulawentah

mendidik karakter menurut Aunillah, 2011: 22-23) adalah nilai universal yang dapat digali dari nilai-nilai dasar budaya bangsa (termasuk di dalamnya religi, kesenian, ilmu pengetahuan, dan sebagainya) yang disepakati oleh para pakar. Nilai-nilai tersebut diantaranya; jujur, disiplin, percaya diri, peduli, mandiri, gigih, tegas, bertanggung jawab, kreatif, dan bersikap kritis.

Dengan demikian, jika kesenian Dongkrek Madiun memiliki nilai-nilai adilihung maka berpotensi untuk dijadikan sumber pendidikan karakter bagi generasi muda.

\section{Metode Penelitian}

Penelitian ini menggunakan pendekatan kualitatif etnografis yaitu usaha meneliti suatu kelompok kebudayaan tertentu yangdalampengolahan data, sejak mereduksi, menyajikandan memverifikasi serta menyimpulkan data, tidak menggunakan perhitunganperhitungan secara matematis dans tatistik, melainkan lebih menekankan pada kajian interpretatif. Adapun tipe etnografisnya yang dipakai adalah etnografi kritis dimana studinya diarahkan untuk meneliti sistem kultural masyarakat dalam hubungannya dengan Kesenian Dongkrek dengan memanfaatkan data emik (pandangan informan) dan data etis (pandangan peneliti) pada nilai kesenian Dongkrek dan potensinya sebagai sumber membangun karakter.

Penelitian ini dilaksanakan di Kabupaten Madiun mulai bulan AprilNopember 2016. Sumber penelitian menggunakan sumber primer yang berupa informasi dari para informan, dan sumber skunder yang berupa dokumentasi, laporan-laporan tertulis, dan lain sebagainya. Adapun penentuan informan dengan teknik purposive sampling. Sedangkan pengumpulan datanya menggunakan wawancara, observasi, pencatatan dokumentasi. Untuk memeriksa validitas data, peneliti menggunakan teknik triangulasi sumber. Sedangkan analisis datanya dengan Teknik Coding Model Strauss dan Corbin yang terdiri tiga jenis pengkodean yaitu opencoding, axialcoding, dan selectivecoding.

\section{Hasil Penelitian dan Pembahasan}

Kesenian Dongkrek merupakan seni perpaduan antara seni tari, seni, musik, seni topeng, dan seni ceritera (drama) yang biasanya dipertunjukan dengan arak-arakan keliling kampung. Kesenian Dongkrek yang berupa arak-arakan biasanya melibatkan masyarakat bukan sebagai penonton tetapi sebagai pelaku budaya turut menari.

Asal-usul kesenian Dongrek menurut Wahyuningsih dkk (2012) dapat dirunut melalui tembang gambuh:

Keparengo amatur//Sekar gambuh amurwani atur//Seni dongkrek angirto dongkrek kang asli//Ngleluri budoyo luhung//Ciptane leluhur kito Semangke kang cinatur//Riwayat dongkrek engkang asli//Asal saking Dusun Menjayan kang asli//Palang kaleng-gahanipun//Priyo luhur kang yosoJamane kang kapungkur//Duk semono Menjayan kang usun// Katrajang eng pagablug akeh pepati// Tambah-tambah polah ipun//Kawulo ngudi usodo Berkah kang Moho Agung//Eyang Palang hang sakti kalangkung//Metu broto angento dongkrekmauwarni//Kinaryo mbrasto pageblug//Serno tapis tanpo siso Suko sukur yang Agung//Poro kawulo bingah kalangkung//Eyang Palang aparing dawuh sayekti//Istinen budoyo luhung// Nirkolo suko raharjo. 


\section{gulawentah: Jurnal Studi Sosial}

Volume 1 Nomor 2 Desember 2016, hal. 132-141

Avaliable online at http://e-journal.ikippgrimadiun.ac.id/index.php/gulawentah

Kesenian Dongkrek dicipta oleh oleh Raden Bei Lo Prawirodipura yang saat itu menjadi demang (jabatan setingkat kepala desa) yang membawahi lima desa di daerah Caruban yang sekarang menjadi Kecamatan Mejayan Kabupaten Madiun. Pada tahun 1879-an daerah Caruban mengalami krisis pangan (pageblug) dan terjangkit wabah penyakit mematikan. Dalam situasi dan kondisi yang memprihatikan ini, Raden Prawirodipuro melakukan ikhtiar dengan cara meditasi atau bertapa di gunung kidul Caruban. Ia kemudian mendapatkan wangsit bahwa krisis pangan dan wabah penyakit yang terjadi akibat bala dan ulah dari kerajaan makhluk halus yang jahat atau pasukan gendruwo. Oleh sebab itu dilawan dengan cara mengusirnya. Untuk menolak bala dan mengusir makhluk halus yang jahat dan pasukan gendruwa perlu alat maka dari itu diciptakan kesenian yang melukiskan fragmentasi pengusiran roh halus jahat atau gendruwa.

Komposisi pertunjukan fragmen satu babak pengusiran roh halus terdiri dari barisanbutha (dari bahasa Jawa yang berarti buto atau raksasa), orang tua sakti, dan dua perempuan paruh baya.

Perempuan ini menyimbolkan kondisi rakyat yang lemah karena dikepung oleh para pasukan butha Kala. Sebelum pasukan butha berhasil mematikan para perempuan, muncul sesosok lelaki tua sakti yang dengan tongkatnya berhasil mengusir para barisan roh halus untuk pergi menjauh. Selanjutya terjadi peperangan cukup sengit antara rombongan butha dengan orang tua sakti, yang dimenangkan oleh si lelaki sakti. Rombongan butha yang kalah akhirnya menurut dan patuh. Si orang tua sakti yang didampingi dua perempuan menggiring pasukan butha kala keluar dari Desa Mejayan dan sirnalah pageblug.

Kesenian ciptaan Raden

Prawirodipuro dinamakan dongkrek oleh masyarakat didasarkan pada suara alat-alat musik pengiring kesenian tersebut. Tetabuhan musik terdengan "dung" yang berasal dari beduk atau kendang dan "krek" dari alat musik yang disebut korek (kayu berbentuk bujur sangkar dengan satu ujungnya terdapat tangkai kayu bergerigi yang saat digesek berbunyi krek). Dari bunyi alat itulah kemudian membudaya esenian tersebut dengan nama Dongkrek. Dalam perkembangannya, alat-alat musiknya ditambah gong, kenung, kentongan, kendang, dan gong berry sebagai perpaduan budaya Islam, budaya Cina, dan kebudayaan masyarakat Jawa pada umumnya.

Pertunjukan kesenian Dongkrek memiliki sifat antara lain; (1) sakral yaitu digunakan sebagai upacara ritual tolak bala. Dongkrek ini hanya dipentaskan setahun satu kali, dengan acara arak-arakah yang melibatkan seluruh masyarakat desa Mejayan. Saggar kesenian Dongkrek yang masih mempertahankan pakem atau keaslian seni Dongkrek tanpa adanya perubahan adalah sanggar Dongkrek "Krido Sakti" pimpinan Walgito (2) kreasi seni (kreatif) sebagai kesenian rakyat yang tidak sakral, tidak ada kemenyan, tidak ada persyaratan dari keturunan palang Ngabehi Lho Prawirodipoero "Palang Mejayan", dengan iringan musik yang lebih ramai. Dongkrek ini masih ada arak-arakannya dan melibatkan masyarakat untuk bergabung dan menari, serta bisa diundang untuk melakukan pertunjukan dan 


\section{gulawentah: Jurnal Studi Sosial}

Volume 1 Nomor 2 Desember 2016, hal. 132-141

Avaliable online at http://e-journal.ikippgrimadiun.ac.id/index.php/gulawentah

mendapatkan upah, (3) seni pertunjukan tidak sakral, tidak ada kemenyan, tidak melibatkan masyarakat untuk menari, tidak ada arak-arakan, tidak keliling kampung, dan tidak ada persyaratan dari keturunan "Palang Mejayan", dengan iringan musik yang lebih banyak dan dipertunjukan di studio atau panggung.

Walaupun pertunjukan kesenian Dongkrek memiliki sifat yang berbedabeda sebagaimana yang disampaikan di atas namun masih memiliki nilai budaya yang sama yaitu kejahatan akan kalah dengan kebajikan, sura dira jayaningrat lebur dening pangastuti (semua perbuatan jahat akan kalah oleh perbuatan yang baik dan bijaksana).

Nilai budaya kesenian Dongkrek tidak hanya terpotret pada framen cerita dramanya saja tetapi juga pada mkana topeng yang dikenakan ketika pelaksanakan pertunjukan. Topeng sebagai ilustrasi watak dari perilakunya yang dimaksud yaitu

Tabel 1. Topeng Kesenian Dongkrek

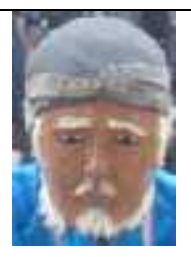

Topeng Raden Prawirodipura

Menggambar watak ksatria, bijak, dan kuat lahir-batin

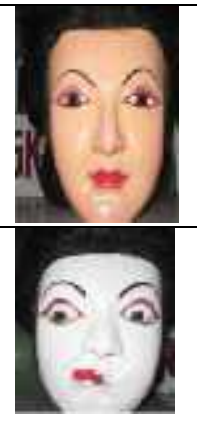

Topeng Roro Ayu

Menggambarkan wanita yang cantik (putri pejabat) yang anggun, sopan dalam berbicara, perilaku, dan selalu berbuat kebaikan

Topeng Roro Perot / Wewe Putih.

Menggambarkan wajah dari abdi kinasih (pengikutsetia) RadenPrawirodipoero yang berwatak ajeg atau berpendirian teguh tidakmudah terpengaruh oleh orang lain, kemampuan yangdimilikinya,pantang menyerah dapat diandalkan, jugasangatsetia.

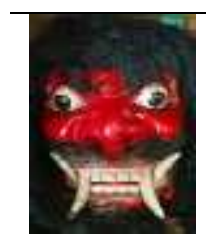

Topeng Genderuwa Merah.

Menggambarkan watak yang mudah marah, emosional, kasar, kaku dan sukamembuat masalah dengan yang lainnya.

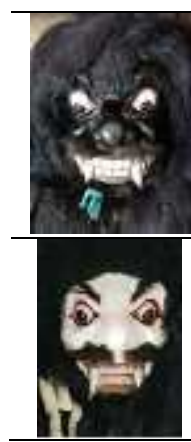

Topeng Genderuwa Hitam

Menggambarkanwatak

buruk. Memiliki watak sifat pemalas, suka makanbanyak namun malas untuk bekerja.

\section{Topeng Genderuwo Putih}

Menggambar watak yang baik, memiliki tatakrama dan manusiawi. Warna putih diwariskan dari sumber kehidupan yaitu air, yang mengalir bening, bersih, ternih dan menyucikan. 


\section{gulawentah: Jurnal Studi Sosial}

Volume 1 Nomor 2 Desember 2016, hal. 132-141

Avaliable online at http://e-journal.ikippgrimadiun.ac.id/index.php/gulawentah

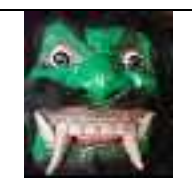

Topeng Genderuwo Hijau

Menggambar watak yang hampir sama dengan genderuwo hijau, ksatria, berani bertanggung jawab, santun, namun hanya sebagai penutup atas kemegahan dan kemewahan atas keberadaanharta dan benda.

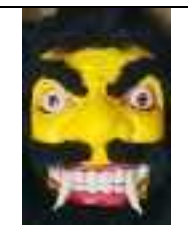

Topeng Genderuwo Kuning

Menggambar watak sebagaimana genderuwo hijau, watak/nafsu supiah yang berjiwa ksatria, berani menanggung dosa,memiliki tata krama dan manusiawi namun bersifatduniawi dan memuja keindahan dan kemewahan harta.

Makna dari topeng di atas sejalan dengan hasil temuan Cahyani (2015) bahwa karakter pelaku dalam cerita dongrek diilustrasikan dalam perwajahan topeng yang mencerminkan watak atau karakter aktornya

Alat-alat pengiring atau musik untuk mengiringi pertunjukan kesenian Dongkrek juga memiliki makna simbolik, yaitu

\section{Tabel 2 Makna Simbolik Alat Musik Kesenian Dongkrek}

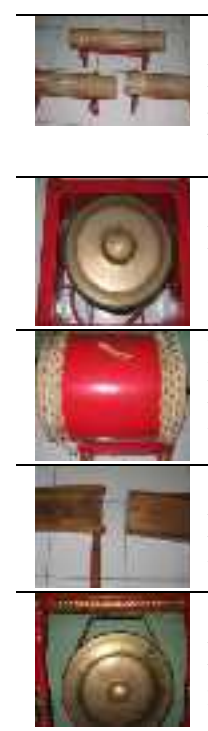

Kentongan

Maknanya sebagai suatu tanda untuk mengumpulkan atau menggerakkan masyarakat guna bersatu padu (Saye sa eko proyo). Dengan suara thok thok diilustrasikan seperti titir (penanda bunyi sebagai media penyampai pesan)

Kenong

Maknanya sebagai pengantar suasana hening, cipta, karsa, karya kepada Sang Pencipta.

\section{Bedug}

Maknanya untuk menggambar-kan kesaktian Palang Mejayan sebagai pendekar pilih tanding, "ora tedas tapa paluning pande" (dug deng).

\section{Korek}

Maknanya sebagai alat pembersih/penyapu segala macam mara bahaya baik yang terlihat maupun yang tidak terlihat.

\section{Gong}

Maknanya Raden Prawirodipura sebagai seorang yang berbudi wibowo laksono, rawe-rawe rantas malang-malang putung bersama-sama memberantas penyakit pageblug.

Melihat dari fragmen cerita, watak pelaku cerita, dan alat musik pengiring pertunjukan Dongkrek di atas maka dapat disampaikan bahwa kesenian Dongkrek memiliki nilai-nilai diantaranya:

1. Nilai kerohanian kesenian dongkrek ditunjukan pada prosesi kesenian Dongkrek adalah untuk pengusiran pageblug (tolak bala), dilakukan dengan cara: (a) para parogo pilihan, yang dipandang mampu untuk melakukan upacara ritual tersebut didatangkan lebih dahulu di pendopo palangan, untuk mendapatkan petunjuk dari eyang palang; (b) Para parogo mulai lelampah menurut petunjuk yang telah ditentukan; (c) pada malam yang telah ditentukan, yaitu malam jumat legi, semua parogo berkumpul di pendopo mengadakan selamatan untuk memohon berkah kepada Tuhan Yang Maha Esa atas telah terjadinya perbuatan gendruwo; dan (d) saat tepat tengah malam dengan iringan mantra dan puji-pujian, 


\section{gulawentah: Jurnal Studi Sosial}

Volume 1 Nomor 2 Desember 2016, hal. 132-141

Avaliable online at http://e-journal.ikippgrimadiun.ac.id/index.php/gulawentah

diberangkatkanlah serombongan prosesi ritual pengusiran pagebluk itu di pendopo dalem palangan, berjalan pelan-pelan menyusuri jalan-jalan di seluruh pelosok desa Mejayan, sampai waktu menjelang pagi. Sedangkan nilai magisnya ditunjukkan prosesi ritual keliling desa ini para parogo Dongkrek khususnya parogo gendrowon wajib untuk tidak mengenakan busana (semua parogo terdiri dari kaum laki-laki). Adapun aturan prosesi ritual ialah: (a) obor terbuat dari bambu; (b) dupa yang selalu mengepulkan asap bau kemenyan yang dibawa oleh pembaca mantra; (c) pusaka palangan yang dibawa oleh waris terpilih dibawah Payung Agung (pusaka palangan); (d) beberapa syarat tolak bala yang lain, bermacam-macam tumbal dan takhir plontang yang berisi bermacam bubur beras dan ditanam di tempat-tempat yang telah ditentukan, seperti di perempatan jalan, pertigaan dan di sudut-sudut desa; (e) gendruwon dan peralatan lainnya; dan (f) para sesepuh yang gamben-gamben (berilmu tinggi).

2. Nilai spiritualdalam kesenian Dongkrek mengandung unsur spiritual yang memuat nilai-nilai Jawa yang adiluhung.Kesenian Dongkrek menjadi tontonan dan tuntunan bagi masyarakat dengan pesan sura dira jaya ningrat, ngasta tekad darmastuti (setiap kejahatan pada akhirnya akan kalah juga dengan kebaikan dan kebenaran).

3. Nilai moral kesenian Dongkrek dirungkapkan pada setiap pertunjukan ada upaya membangun jiwa kebersamaan, kerukunan, dan kegotongroyongan.
4. Nilai simbolik dalam kesenian Dongkrek ditunjukan dari simbol perlawanan kejahatan dan keangkaramurkaan yang dapat dilihat pada fragmen arti cerita pertunjukan, topeng pemain lakon, dan alat-alat musik pengiring pertunjukan.

5. Nilai kepahlawanan dalam kesenian Dongkrek digambarkan oleh eyang palang sebagai pemeran tokoh Raden Tumenggung Prawirodipoero yang berani berjuang dan rela berkurban melawan buto/gendruwountukmenyelamat-kan rakyatnya dari pageblug.

6. Nilai kepemimpinan dalam kesenian Dongkrek terlihak pada eyang palang sebagai pemeran Raden Tumenggung Prawirodipoero yang memimpin rakyat Desa Mejayan dengan arif, penuh tanggung jawab, dan bijaksana.

7. Nilai keadilan dalam kesenian Dongkrek terdapat pada hakikat yang menjadi tujuan kesenian ini yakni menerapkan keadilan dalam bermasyarakat dengan pemenuhan hak dan kewajiban. Pemenuhan hak dan kewajiban menurut hakikat dan kodratnya sebagai makhluk individu, makhluk sosial, dan makhluk Tuhan.

8. Nilai kesejahteraan dalam kesenian Dongkrek dimaknai dengan kehidupan yang tenteram, makmur, dan damai.

9. Nilai estetika dalam kesenian Dongkrek ditunjukan oleh gerak tari para pemain, tata busana, tata rias, dan aransemen musik pengiringnya.

Nilai-nilai kesenian Dongkrek sebagaimana disampaikan di atas dapat dikaitkan dengan pembentuk karakter. 


\section{gulawentah: Jurnal Studi Sosial}

Volume 1 Nomor 2 Desember 2016, hal. 132-141

Avaliable online at http://e-journal.ikippgrimadiun.ac.id/index.php/gulawentah

Nilai kepemimpinan dan nilai kepahlawanan dapat direfleksikan ke arah pembangunan karakter bangsa. Fungsi ekspresi dan instrumental dalam kesenian Dongkrek mempunyai peran yang sangat penting dalam menumbuhkan karakter, khususnya bagi para pemainnya. Pada pertunjukan kesenian Dongkrek, para pemain dituntut untuk tekun berlatih, bergotong royong, saling menghargai dan selalu menjunjung tinggi budaya. Fungsi ekspresi menunjukkan bahwa kesenian Dongrek mempunyai peran peran sebagai pelestari budaya, sedangkan fungsi instrumentalnya kesenian Dongkrek sebagai penyampai pesan yang terkait dengan kebajikan dan pesan moral yang baik lainnya.

Nilai-nilai kesenian dongkrek yang ditemukan dalam penelitian ini tidak berda jauh dengan hasil penelitian Hartini (2012). Bahkan jika ditelaah lebih dalam nilai--nilai dalam kesenian dongkrek sesuai dengan nilai-nilai Pancasila yaitu: (1) Kepercayaan sesuai dengan nilai ketuhanan, (2) Nilai kepribadian sesuai dengan nilai kemanusiaan, Nilai hiburan dan pertunjukan sesuai dengan nilai persatuan, (4) Nilai sosial atau kerukunan sesuai dengan nilai kerakyatan, (5) Nilai kesejahteraan dan kelestarian sesuai dengan nilai keadilan.

\section{Kesimpulan}

Kesenian dongkrek memiliki nilainilai; kerohanian, spiritual, moral, kepahlawanan, kepemimpinan, keadilan, kesejahteraan, dan estetika. Nilai-nilai secara fungsional dan eksperimental berpotensi untuk dijadikan sumber pendidikan karakter terutama dalam penegakan nilai-nilai masyarakat, kehidupan berbangsa dan bernegara, serta menumbuhkembangkan jiwa kepemimpinan, kepahlawanan, keikhlasan, dan kesetiaan seperti yang tergambar dalam watak Raden Prawirodipura dan Roro Ayu.

Mengingat kesenian Dongkrek mempunyai nilai-nilai adiluhung maka perlu dikembangkan internalisasi agar generasi muda mencintai dan mentransformasi nilai untuk bersikap dan bertindak.

\section{Daftar Pustaka}

Aunillah, N.I. (2011). Panduan Menerapkan Pendidikan Karakter di Sekolah. Jakarta: Transmedia.

Cahyani, I.D. (2015). Karakteristik Topeng Dongkrek Sanggar Krido Sakti di Kecamatan Mejayan Kabupaten Madiun, Jurnal Pendidikan Seni Rupa, Volume 3 Nomor 2 Tahun 2015. Surabaya: UNNESA

Hartini. (2012). Kajian Nilai, Fungsi, dan Makna yang Terkandung Dalam Seni Dongkrek, Premiere Educandum Jurnal Pendidikan Dasar dan Pembelajarannya Volume 2 Nomor 2/2012. Prodi PGSD IKIP PGRI MADIUN

Hatta, M.F. (2010) Membangun Ketahanan Bangsa. Melalui Kesenian. www.bappenas.go.id/

index.php/download_file.

Jaecken M.P. (2011). Seni Dongkrek Kecamatan Mejayan Kabupaten Madiun Tahun 1965-1981. Laporan Hasil Penelitian. Surakarta: UNS

Kesuma, D. dkk. (2011). Pendidikan Karakter, Kajian Teori dan Praktek di 


\section{gulawentah: Jurnal Studi Sosial}

Volume 1 Nomor 2 Desember 2016, hal. 132-141

Avaliable online at http://e-journal.ikippgrimadiun.ac.id/index.php/gulawentah

Sekolah. Bandung: PT Remaja Rosdakarya.

Koetjaraningrat. (2009). Pengantar Ilmu Antropologi (Edisi Revisi 2009). Jakarta: PT Rineka Cipta.

Kutanegara, P.M. dkk. (2012). Revitalisasi

Kesenian Dongkrek dalam Rangka

Ketahanan Budaya Lokal: Studi

Kesenian Dongkrek Desa Mejayan

Kecamatan Mejayan Kabupaten

Madiun. Yogyakarta: Balai Pelestarian

Nilai Budaya (BPNB) Daerah

Istimewa Yogyakarta dan Fakultas Ilmu Budaya, Universitas Gadjah Mada.

Pretisa, G. dan Susetyo, B. (2013). Bentuk

Pertunjukan dan Nilai Estetis Kesenian Tradisional Terbang Kencer Baitussolikhin. Jurnal Seni Musik Nomor 2 Volume 2 Tahun 2013. Semarang: Unnes.

Sutiyono. (2012). Paradigma Pendidikan Seni di Indonesia. Yogyakarta: UNY Press.

Setia, B. (2015). Dongkrek Upacara Mengusir Pageblug. Jakarta: Direktorat Kepercayaan Terhadap Tuhan YME dan Tradisi Direktorat Jenderal Kebudayaan Kementerian Pendidikan dan Kebudayaan

Simatupang, L. (2013). Pergelaran Sebuah Mozaik Penelitian Seni-Budaya. Yogyakarta: Jalasutra.

Uhi, J.A. (2016). Filsafat Kebudayaan, Konstruksi Pemikiran Cornelis Anthonie van Peursen dan Catatan Reflektifnya. Yogyakarta: Pustaka Pelajar.

Wahyuningsih, S., dkk.(2012) Revitalisasi Seni Pertunjukan Dongkrek sebagai Upaya Penguatan Identitas Daerah dan Pengembangan Aset Wisata Budaya di Kabupaten Madiun Jawa Timur.Laporan Hasil Penelitian. Surakarta: UNS 